\title{
EMPOWERING FISH FARMERS AND PROCESSORS TO COPE WITH THE CHALLENGES OF COVID-19 PANDEMIC: THE ROLE OF NIGERIAN STORED PRODUCTS RESEARCH INSTITUTE (NSPRI)
}

\author{
Omodara MA*, Adetayo SA, Oyewole SN, Adeiza AO, Adegbola \\ JA, Atibioke OA and Pessu PO \\ Nigerian Stored Products Research Institute, Km 3 Asa Dam Road, PMB 1489, Ilorin \\ Kwara State, Nigeria
}

\begin{abstract}
COVID-19 pandemic has impacted the whole word in several dimensions leaving the fishing communities in the rural areas more vulnerable. A huge proportion of this fishing communities derive their income from the sale of fish that are caught and processed using local smoking equipment. The lockdown occasioned by the pandemic has really made life difficult for this people. In responding to these challenges, Nigerian Stored Products Research Institute (NSPRI), an agency of the federal government of Nigeria built fish processing facilities for fish farmers and processors in six (6) different locations spread across Niger and Kwara State. The processing centres were constructed as a facility where all the unit operations from receiving fresh fish to packaging of dried fish can be carried out under hygienic condition. The centres were equipped with NSPRI's improved smoking kilns, handling and processing utensils, and packaging materials for the marketing of dried fish. Fish farmers and processors in the various locations were trained on proper handling, processing, packaging, and marketing of their products. This intervention has alleviated the sufferings of the concerned communities and brings about a turnaround in their social economic status. The initiative has also improved community engagement among the fish farmers which has increased their output. They can produce better quality product and sell them to buyers in neighbouring towns. This study demonstrated the key role of government in providing succour for rural communities especially in times of pandemic such as COVID-19 that the world is just recovering from.
\end{abstract}

\section{Introduction}

Fish is one of the major animal protein sources available to man across the globe, especially among the developing nations, thus it deserves adequate attention to reduce postharvest loss and increase its safety and availability. This called for intervention from both local and international agencies to achieve this aim. Globally, more than 19.3 million people were estimated as direct smallholder fishermen, accounting for about 96.4 million tons of catch (Harper et al., 2020; FAO, 2020). The estimation in Nigeria comprised both local production (natural and artificial pond sources) and imported fishery products. Most of the processed fish products available in Nigerian markets are locally produced mainly using traditional methods. The use of traditional methods (which involves the use of firewood) resulted in production of unsafe and unhygienic fishery products available in the local market (Akintola et al., 2006). 
However, the Federal Government of Nigeria is funding some National Agricultural Research Institutes (NARIs) to develop postharvest technologies for various food crops (fish inclusive) with potential to minimize postharvest losses and improve income and livelihood of smallholder farmers (Sanni et al., 2012). Some of the developed indigenous technologies by the Nigerian Stored Products Research Institute (NSPRI) in postharvest handling of fisheries are iced fish box ${ }^{\circledR}$, produce dryers, fish smoking kiln ${ }^{\circledR}$, among others. Despite the availability of these technologies, their usage is not yet popular among the fish handlers in Nigeria, thereby leading to production of poor-quality fishery products and high postharvest losses. Adoption of improved fish processing technologies has been identified as a potent means of improving the livelihood of fishing communities (Nti et al., 2002).

Consequentially, there is an increase in widespread of poverty in the country despite the high food production potentials, which is against the principle of sustainable development. This situation got worsened because of the Coronal Virus Disease 2019 (COVID-19) outbreak that necessitated the national lockdown in Nigeria and in many countries of the world to reduce its widespread. This situation therefore requires urgent steps to reactivate and re-channel the course of the nation's agriculture on the path of sustainable growth. However, the inability of the smallholder farmers to acquire the technologies emanating from NARIs poses a great challenge to the goal of achieving sustainable growth via agriculture (Sanni et al., 2012). To combat this, NSPRI being one of the Institutes in NARIs embarked on establishment of Agricultural Research Outreach Centres (AROC) for fisheries. The AROC are mini technology incubation centres, where technologies are made available for the benefiting community's use to popularize such technologies. These centres serve as means of empowering fish handlers that are susceptible to the adverse effects of COVID-19 pandemic, to cushion the socio-economic effects of the disease on them and sustain their livelihood.

\section{The Effects of COVID-19 on Fisheries}

The impact of the outbreak of the coronavirus infection abides as the entire world is still counting the losses. In Nigeria, the effect cut across all sectors including agriculture. As its health risks and high mortality became more apparent, almost all countries including Nigeria implemented lockdowns and travel restrictions. The restrictions, however, collapsed the successful production and supply of food generally (fisheries inclusive). These lockdowns/restrictions on fishing activities precluded many small-scale fisherpersons from going fishing due to vessel size or trading in close quarters in local markets (Orlowski, 2020) thereby, underplaying the role of fish in food systems.

This altered the lifestyle and livelihood of small-scale fishing communities in the nation, while the effect of the COVID-19 might also marginalize many smallholder fisherpersons and coastal communities. There is need for governments, development organizations, NGOs, donors, private sector, and researchers to rapidly mobilize support for small-scale fisherpersons, coastal fishing communities and associated civil society organizations to help them respond to the COVID-19 pandemic.

Consequently, the fish handlers have to make difficult decisions - feeding their families by risking exposure or stay safe with little or no income. Regrettably, the health facilities in the rural coastal communities are to handle mild health cases and maternity issues, but not for complicated cases like COVID-19. Therefore, these rural communities are at risk as they may have reduced immunity and access to sound healthcare (Turkewitz, 2020; Harvey, 2020). 


\section{Government Intervention through NSPRI}

As the consequential effect of restrictions due to COVID-19, Welsh (2020), predicted increase in the proportion of people facing food insecurity as a result of farmers' inability to access agricultural inputs. Communities across West Africa now face the combined effects of COVID-19, chronic hunger, conflict and climate change (Africa Press Office, 2020). Although, various tiers of Nigeria government attempted to cushion the effect of COVID-19 on hunger by distributing some food items to the vulnerable groups, however, animal-based foods such as fish, meat and egg were left out, this further proves the underplaying of the commodity groups.

However, Federal Government of Nigeria through NSPRI focused on coastal communities by establishing modern fish processing centres for the smallholder fish handlers under the Agricultural Research Outreach Centre (AROC) concept. The establishment of these centres is very necessary to gradually face out the poorly and unhygienically processed fish products commonly found in Nigerian markets. The adopted village concept helps to stimulate mass adoption of new technologies among neighbouring communities. The villages are to serve as "showrooms" for convincing intending farmers and other end users on the viability of the technologies being promoted (NSPRI, 2021). Nigeria's research institutes embraced the concept and identified the villages during the intervention of a national research project aimed at increasing agricultural research funding in the country. The project was titled National Agricultural Research Project (NARP). However, the centres could not function as projected after the project fund was exhausted.

It is worthwhile to recall the efforts of government in the past and present to tackle the major problems bedevilling the fisheries sub-sector of agriculture. These include Lake Chad Project for Improvement of Fish Processing and Transportation (1975 - 1982), Federal Fisheries Schools Project (1976 - 1985), Artisanal and Inshore Fisheries Development Project (1979 - 1987), and National Accelerated Fish Development Project (1979 - 1983). Recent efforts include the Fisheries Estate Project (FEP) and Presidential Initiative on Aquaculture (PIA) in 2005 (FAO, 1992; FAO, 2020).

Specifically, key activities in the fisheries or aquaculture value chain are fishing, aquaculture production, value addition, transportation, and marketing. Each stage of the chain is susceptible to being disrupted or stopped by impacts arising from COVID-19 and related measures. If one of these buyers-sellers links is ruptured by the disease or containment measures, the outcome will be a cascading chain of disruptions that will affect livelihoods and food security. It has been reported that there will be reduced spending by households experiencing financial distress (HLPE, 2020). Also, the wild and farmed aquatic food sectors, along with most industries, must deal with an uncertain demand outlook as well as an array of supply challenges. With the effective shutdown of the restaurant industry in many places because of restrictions of movement, food service demand has reduced substantially, while retail sales have been marked by extreme volatility as reported in some developed economies such as France, Italy, and Spain, which declined by 30 percent (GFCM, 2020).

In the light of these, the aim of the intervention was to empower fish farmers to cope with the challenges of COVID-19 pandemic. Specifically, this intervention sought to; promote improved fish processing techniques among rural people, eliminate drudgery and health hazards associated with traditional processing practices and enhance the livelihood of the fish farmers in the coastal communities, and build the resilience of the fish farmers to survive the effect of COVID-19. 


\section{Methodology}

\section{The Concept of Agricultural Research Outreach Centre (AROC)}

AROC is a program that gives room for the agricultural actors at the various grassroot levels to access and participate in agricultural technology and innovation formation development. AROC or otherwise called Adopted village initiative is specifically conceived by the Federal Government of Nigeria which avoided the weaknesses and shortcomings of the conventional methods of technology transfer to farmers through the extension staff of the Agricultural Development Projects (ADP). AROC is established at a community or formal learning centre to exhibit a chosen technology for awareness creation to the neighbouring communities and visitors for the purpose of enhancing its adoption. In this quest, over the years, NSPRI has established about thirty (30) AROC Centres across the six geopolitical zones of the country. NSPRI, being a research institute saddled with the responsibility of preventing food postharvest losses and ensuring food safety, has generated various postharvest technologies over the years. Some of these technologies include NSPRI improved smoking kiln ${ }$, ice fish box ${ }^{\circledR}$, improved inert atmosphere silo ${ }^{\circledR}$, hermetic metal drum, dryers, improved ventilated yam barn, cassava storage facilities, stackable/nestable ventilated plastic crate, vegetable baskets, and evaporative coolers, among others.

\section{Selection of Locations}

The locations of the fish processing centres were selected based on the preponderance of fishery activities. A three-stage sampling technique was used to select the locations for the centres. The first stage involved purpose selection of Niger State due to the passage of River with many of its settlements being actively engaged in fishing. The second stage involved purposive selection of three (3) communities with preponderance fishing activities across the riverbanks. And the last stage involved random selection of beneficiaries from the list of the fish farmers / processors in each of the three (3) selected community. The communities selected are Tatabu (Mokwa Local Government Area), Tsafa (Mokwa Local Government Area) and Malale (Borgu Local Government Area). Tatabu and Tsafa are both located along Mokwa-Jebba highway and are about $15 \mathrm{~km}$ and $20 \mathrm{~km}$ away from Mokwa city respectively, while Malale is located at the extreme end of Borgu and it is $177 \mathrm{~km}$ away from Mokwa. The locations of the communities are shown in Figure 1. A total of thirty-nine (39) fish farmers were selected to participate in the train the trainer's exercise. The distribution of the selected participants is presented in Table 1.

Table 1: Distribution of the Beneficiaries of NSPRI's Intervention in the Three Communities

\begin{tabular}{|c|c|c|}
\hline Local Government & Community & Number of direct Beneficiaries \\
\hline Mokwa & Tatabu & 14 \\
\hline Mokwa & Tsafa & 12 \\
\hline Borgu & Malale & 13 \\
\hline Total & & 39 \\
\hline
\end{tabular}



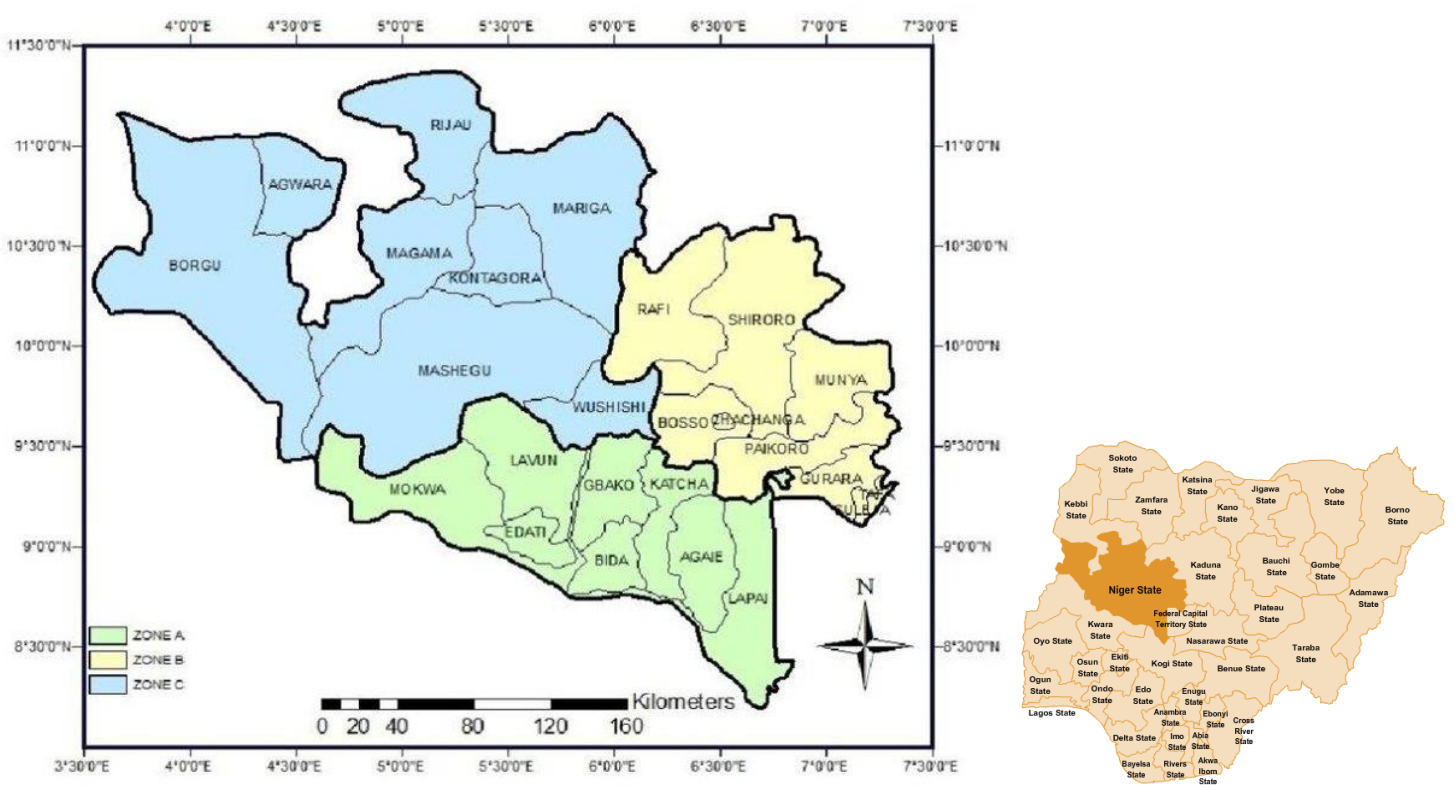

Figure 1: Map Niger state, Nigeria showing the Agricultural zones.

\section{Description of NSPRI Smoking Kiln ${ }^{\circledR}$}

This is an efficient technology for fish drying. It consists of the drying chamber with drying trays, combustion chamber and the oil collector. The smoking kiln developed in NSPRI are classified based on detachability and heat source. It could be detachable or non-detachable. The detachable model can be dismantled into panels for ease of transportation and relocation of the kiln. NSPRI smoking kilns could be powered with charcoal, gas or electricity depending on the client and his/her customers' preference. The equipment is gender friendly and does not require any special training to operate. There are various capacities to suit stakeholders' preference. The fish dried using NSPRI smoking kiln ${ }^{\circledR}$ is of high quality with golden brown appearance depending on types of fish (Omodara et al., 2016) with low polycyclic aromatic hydrocarbons (PAHs) that is within the international permissible limit. The oil collected during drying can be used in pharmaceutical industries (Dada et al., 2020). The income that will be generated from the sales of fish oil will contribute to economic return on investment for the owner. The technology has been patented and a lot of fish farmers and processors have adopted it as essential equipment in their fish value addition business.

The specific kiln used for this intervention was the $50 \mathrm{~kg}$ non-detachable model. The model has a structural dimension of $1200 \times 600 \times 1200 \mathrm{~mm}$. Its inner and outer walls were constructed of galvanized sheet and coated mild steel plate respectively. It has an insulation thickness of $25 \mathrm{~mm}$ lagged with polyurethane material to prevent heat loss and hazard when in use. The kiln has five (5) trays of dimensions $1350 \times 535 \mathrm{~mm}$ made of square pipe and galvanized mesh of $50 \times 25 \mathrm{~mm}$ opening. The kilns provided for COVID-19 intervention for the fisher folks were based on availability and affordability of energy sources (electricity and charcoal) in the area. 

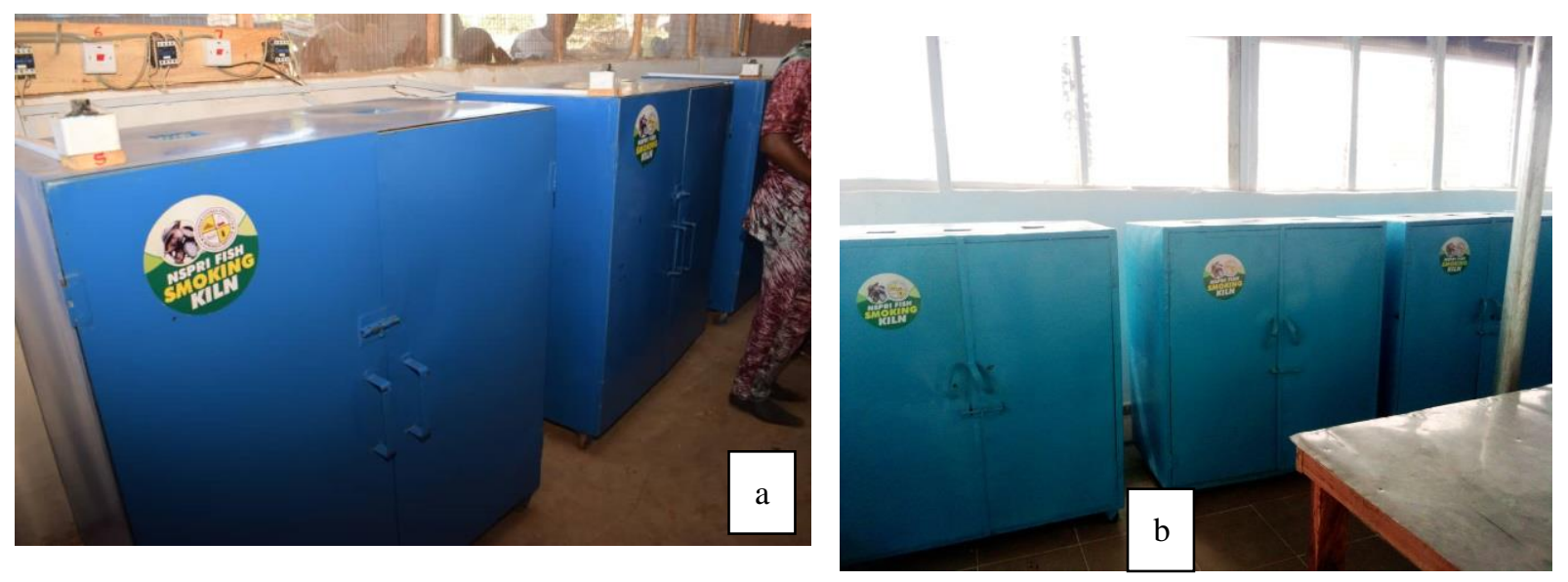

Figure 2: NSPRI Smoking Kilns in the Fish Processing Centres. a. Electricity powered type, $b$. Charcoal powered type

\section{Training Approach}

One of the observations made before the intervention was that the fish processors in the three communities lack knowledge on improved fish processing technique in terms of hygiene, food safety and good quality product. Majority of them were found preparing the fish to smoke on bear ground (Figure 2a). Aside from this, they were using traditional kilns resulting in poor quality products (Figure $2 b$ ). They usually incur high losses because the fish quality could not attract good price, the health of people patronizing them was also at risk. The health risk becomes very important in the phase of COVID-19 pandemic as more people are now careful with what they eat. This greatly affected the income of this people because their patronage was reduced drastically. In view of these, NSPRI thought it imperative to intervene to improve food safety as well as the livelihood of the beneficiaries. After the completion of the construction of the processing centre building in each centre, a 3-day training of the trainers was conducted. The training, which was practical session all through, adopted a participatory approach. The training encompassed all activities involved in safe and hygienic processing of smoked fish. Also, all necessary safety measures were employed during the practical sessions. And at the end, each trainee was certified competence to process fish that meets both local and export standards. 

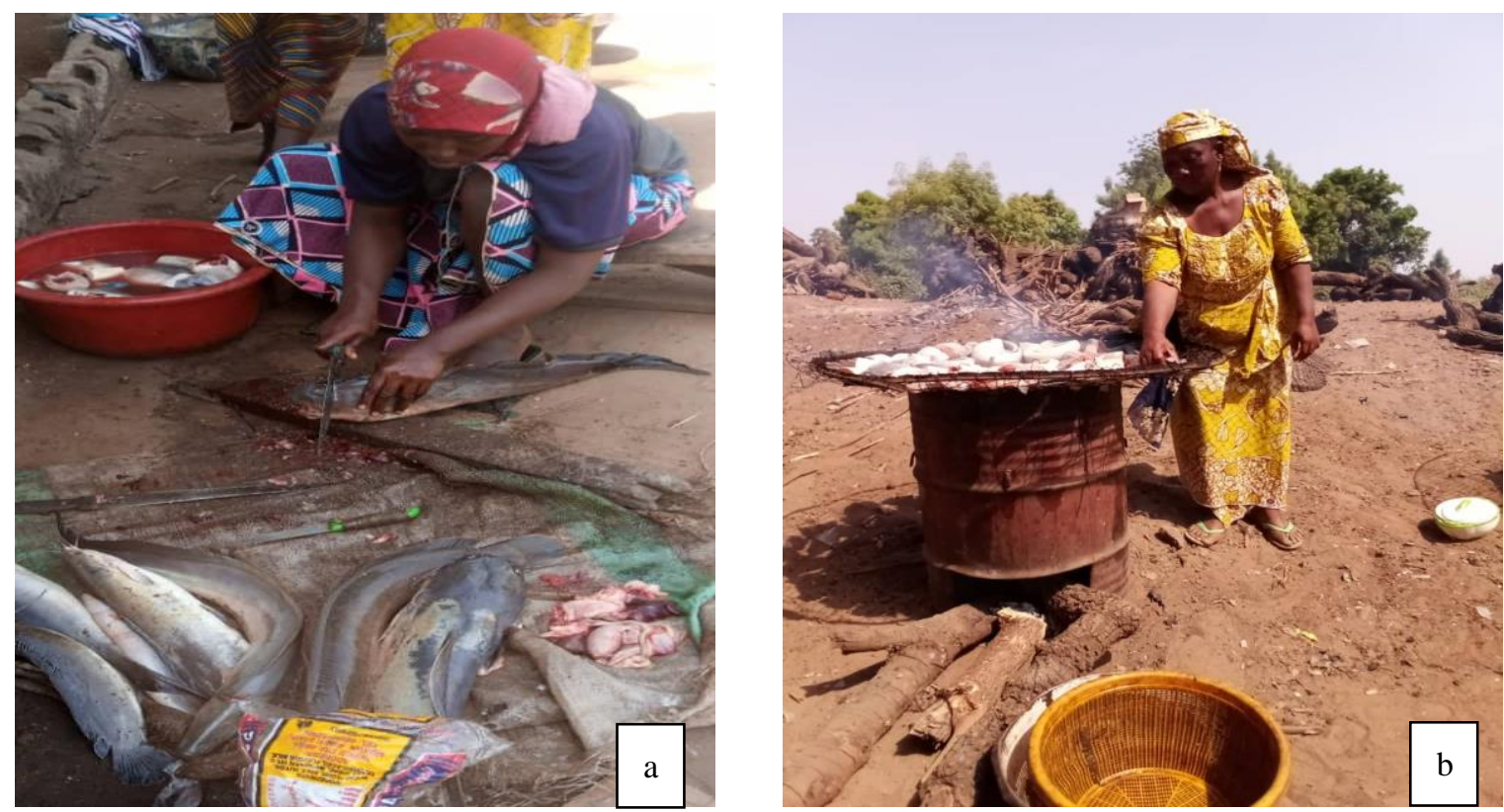

Figure 2: Traditional Smoking of Fish before NSPRI's Intervention. a: Preparation of fish, b: Smoking of Fish

\section{Results and Discussion}

This section presents the results of the socio-economic characteristics of the beneficiaries, the intervention from NSPRI to the communities, and the response of the beneficiaries.

\section{The Socio-Economic Characteristics of the Fish Processors}

The results of the socio-economic characteristics of the fish processors covering gender, occupation, level of education and communication access are presented in Table 2.

Table 2: Frequency distribution of beneficiaries based on socio-economic characteristics $(n=39)$

\begin{tabular}{|l|l|l|l|}
\hline Socio-economic Variables & Parameters & Frequency & Percent \\
\hline \multirow{4}{*}{ Gender } & Female & 26 & 66.7 \\
\hline & Male & 13 & 33.3 \\
\hline & & & \\
\hline \multirow{5}{*}{ Highest Education } & Fish Farming & 15 & 38.5 \\
\hline & Fish Processing & 14 & 35.9 \\
\hline & Crop production & 10 & 25.6 \\
\hline & & & \\
\hline & Never attended school & 25 & 64.1 \\
\cline { 2 - 4 } & Primary & 4 & 10.3 \\
\hline & Secondary & 7 & 17.9 \\
\hline & ND & 2 & 5.1 \\
\hline & BSC & 1 & 2.6 \\
\hline \multirow{5}{*}{ Ownership of mobile phone } & & & 30.8 \\
\hline & No & 12 & 69.2 \\
\hline & Yes & 27 & \\
\hline
\end{tabular}


The results revealed that the fish processors are predominantly female (about 67 percent). It was observed that all the processors in Malale community are male unlike the other two communities. This has to do with cultural beliefs, and it was noted in the other aspects of life of the Borgu people (the indigenous people of Malale community). They do not allow their women to work and be exposed to non-family members, while the other communities have different perspective to this because they are Nupe by tribe. Seventy four percent $(74 \%)$ of the beneficiaries have fishing related activities as the primary source of income (major occupation), while the remaining twenty six percent (26\%) have crop farming as their major occupation.

The results further revealed that sixty four percent (64\%) had no formal education. This is common in rural areas in Nigeria, where majority of the people are illiterate, particularly in the Northern part of the country as corroborated by Simona (2020). More so, sixty four percent (64\%) of the beneficiaries had household dependants that are less than ten (10) people, while thirty six percent (36\%) had more than ten household dependants. This is a common practice in the rural communities in Nigeria where compound family practice is a norm, and they usually take the advantage of the large family size for farming activities as corroborated by Mohammed et al (2020).

On access to social facilities by the beneficiaries, about seventy percent $(70 \%)$ owns mobile phone for communication. This can afford them the opportunity to access information on the handling and marketing of their fish products easily. Over 97 percent of the respondents use pit latrine and open bush defecation as means of excretion practices in the communities. This is a big concern as the practice encourages the proliferation of germs and other safety issues in the community. The most common sources of drinking water in the communities are government water corporation projects and river/stream with almost 85 percent using drinking from the streams. The ownership of personal table water source is very rare in the rural communities because, most of the rural dwellers can either not afford them or take adequate advantage of the political influences around them to attract government water projects to their communities.

The socioeconomic characteristics of the fish processors based on their economic parameters are presented in Table 3. About 80 percent of the beneficiaries' business worth less than N100,000 (about $\$ 245$ USD). This shows that the beneficiaries have weak financial strength to afford a standard processing centre on their own. This stresses the need for an intervention project which was done in this study. Others (20\%), have fishing business worth more than N100,000 this includes the value of their fishing boats, nets and other facilities used for fishing. Consequentially, the returns on their businesses show that more than 70 percent of them realizes less than N5,000 daily on their respective investments as profits. However, with dependants of about ten people, this implies a per capita of less than a dollar a day, which is still far below the WHO poverty line (i.e., per capita of $\$ 1.9$ a day) (Francisco et al., 2015). 
Table 3: Frequency distribution of beneficiaries based on socio-economic characteristics $(n=39)$

\begin{tabular}{|c|c|c|c|}
\hline Other Socio-economic Variables & Parameters & Frequency & Percent \\
\hline \multirow{3}{*}{$\begin{array}{l}\text { Means of transporting children to } \\
\text { school }\end{array}$} & No child in school & 3 & 7.7 \\
\hline & Trekking & 26 & 66.7 \\
\hline & Commercial transport & 10 & 25.6 \\
\hline \multirow{3}{*}{ Type of toilet used at home } & Water Cistern & 1 & 2.6 \\
\hline & Pit latrine & 22 & 56.4 \\
\hline & The bush & 16 & 41.0 \\
\hline \multirow{5}{*}{ Source of drinking water } & River/stream & 13 & 33.3 \\
\hline & Government water corporation & 20 & 51.3 \\
\hline & Well & 4 & 10.3 \\
\hline & Sachet water & 1 & 2.6 \\
\hline & Borehole & 1 & 2.6 \\
\hline \multirow{5}{*}{ Number of Dependants $($ mean $=9)$} & 5 and below & 16 & 41.0 \\
\hline & $6-10$ & 9 & 23.1 \\
\hline & $11-15$ & 5 & 12.8 \\
\hline & $16-20$ & 5 & 12.8 \\
\hline & Above 20 & 4 & 10.3 \\
\hline \multirow{4}{*}{$\begin{array}{l}\text { Worth of the Fish Processing Business } \\
(\text { mean }=\text { N73,615.38) }\end{array}$} & Below N50,000 & 5 & 12.8 \\
\hline & $50,000-100,000$ & 26 & 66.7 \\
\hline & $100,001-200,000$ & 7 & 17.9 \\
\hline & Above N200,000 & 1 & 2.6 \\
\hline \multirow{5}{*}{$\begin{array}{l}\text { Profit on fish processing daily (mean = } \\
\text { N5,061.19) }\end{array}$} & Below 3,000 & 18 & 46.2 \\
\hline & $3,000-5,000$ & 10 & 25.6 \\
\hline & $5,001-10,000$ & 5 & 12.8 \\
\hline & $10,001-20,000$ & 4 & 10.3 \\
\hline & Above 20,000 & 2 & 5.1 \\
\hline
\end{tabular}

\section{NSPRI's Intervention on COVID-19}

NSPRI, constructed a building of $9 \times 6 \mathrm{~m}$ in each of the three selected communities and equipped it with fish value addition technologies and facilities. The beneficiaries in Tatabu community preferred electricity powered kiln because of the availability of the electricity from the national grid in the community. Out of the nine (9) units installed at the centre, seven (7) are electricity powered while the remaining two (2) are charcoal powered in case of power outage during operation. All the kilns installed in the other two communities are charcoal powered because of availability and affordability of charcoal. Other facilities provided to guarantee food safety and hygiene in the centres include fully tiled preparatory section, appropriate plumbing layout to ensure regular supply of water and easy cleaning of the facilities, and stainless cooling table. Others are stores for utensils/materials and finished fish products, cloak room and toilet facility.

Figure 3a shows the processing centre at Tsafa community. The interior of the processing centre with the arrangement of the smoking kilns and the stainless top tables for cooling and packaging of processed fish is shown in figure $3 \mathrm{~b}$. 

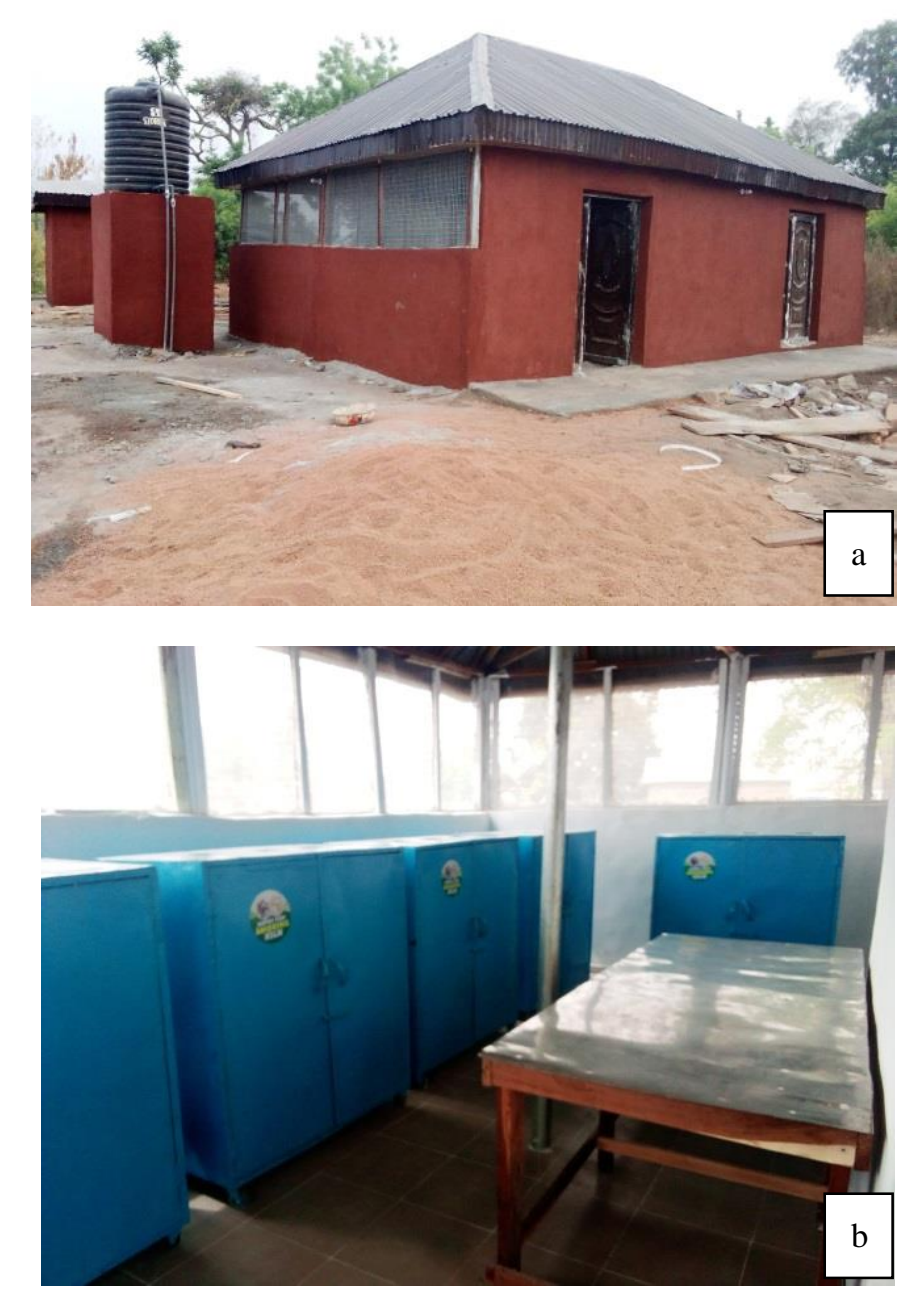

Figure 3: The Fish Processing Centres. a. Diagonal view of the centre at Tsafa; $b$. Interior view of the centre at Malale

\section{Training of the Beneficiaries}

The training, which was full hands-on demonstration covered sanitation and cleaning, preparation of fish, smoking/drying operation, fish packaging and maintenance of smoking kilns. Fifteen (15) participants were trained to ensure fully participation. NSPRI's protocol on preparation of fish for smoking/drying was adopted for the training which the participants commended as a great improvement over their usual practice. The protocol contains collection of fish from farm or river using NSPRI Ice fish box ${ }^{\circledR}$ or appropriate container under hygienic condition. The next operation after collection is killing of fish. This could be done using sharp knife or salt in case of large quantity. The salt will further assist to ease the removal of slime on the body of the fish during washing. To prolong the shelf life of the product after smoking/drying, the participants were taught how to degut the fish to get rid of the intestines and gills that could contribute to early deterioration of the fish product. The process operations following the protocol developed in NSPRI smoked/dried fish are shown in Figure 4. At the end of the processing operations, the participants cleaned all the preparatory tables and the equipment used (Figure 5). 


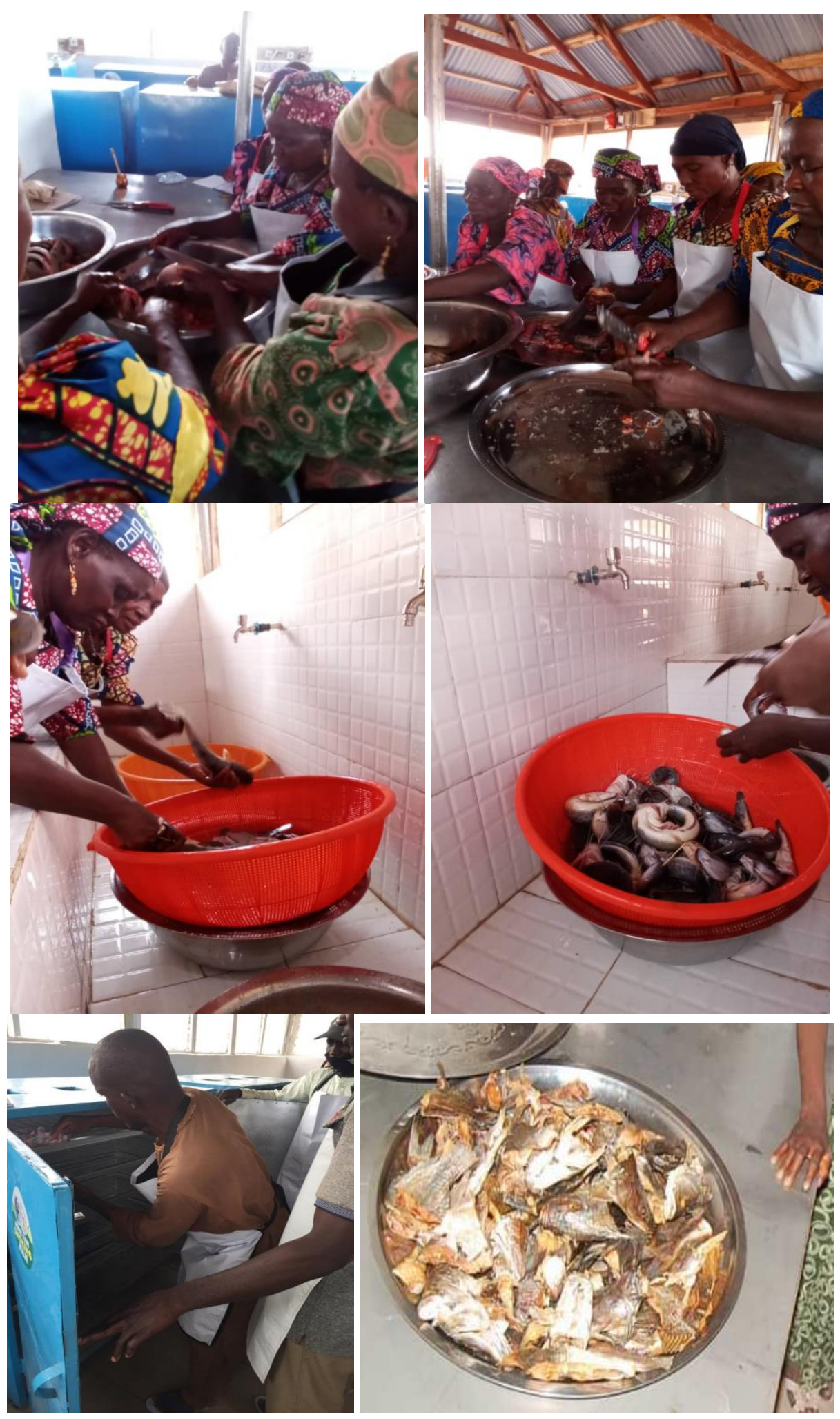

Figure 4: Preparation and smoking/drying of Fish by Participants 


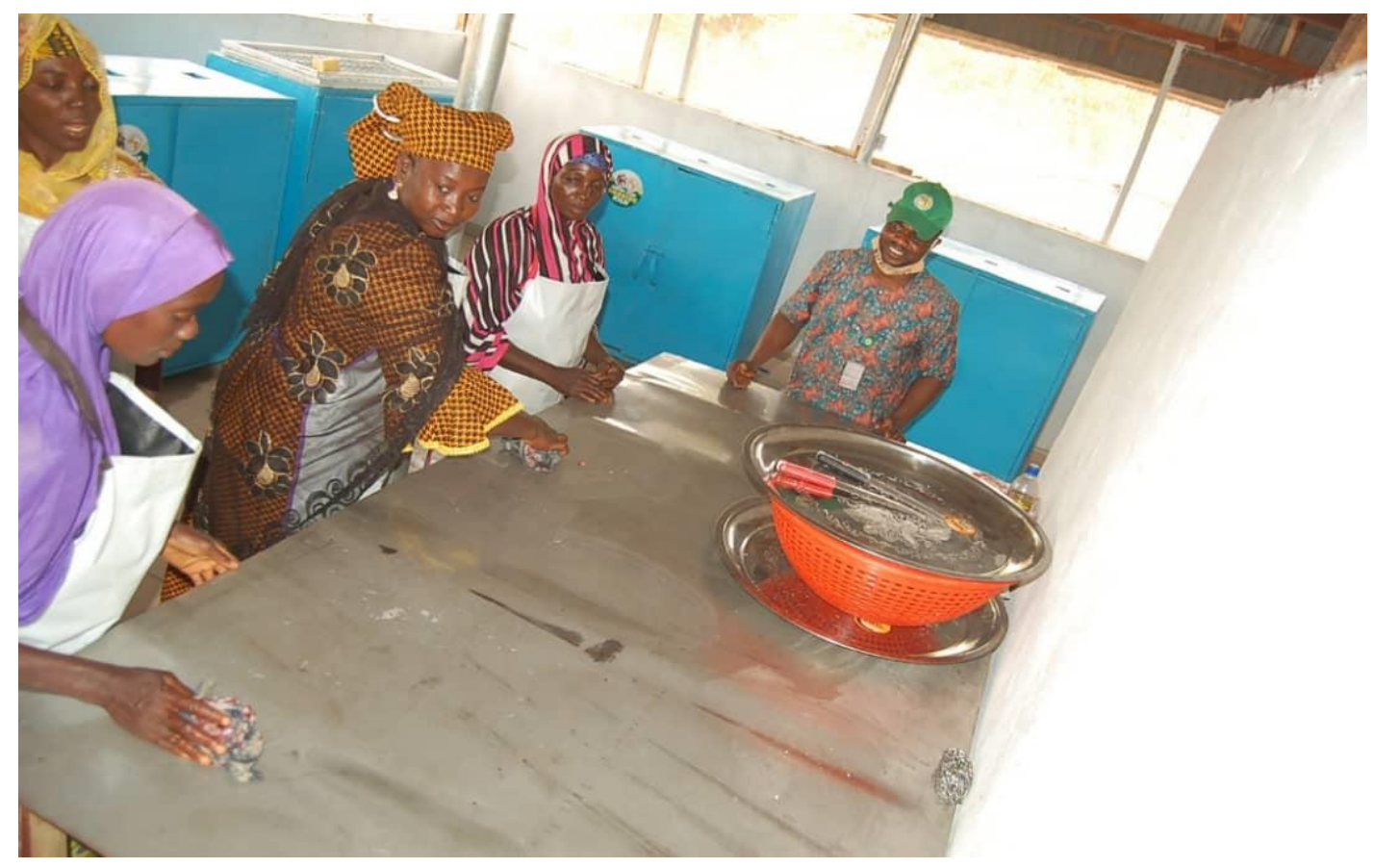

Figure 5: Cleaning of Preparatory Table after Processing Operation by the Participants

Separate trainings were conducted in each community to address their respective peculiarities. In Tatabu, the participants were mostly women. The cross section of the women who benefited from the intervention are shown in figure 6. Participants in Tsafa community were all women (Figure 7) while participants in Malele community were all male (Figure 8).

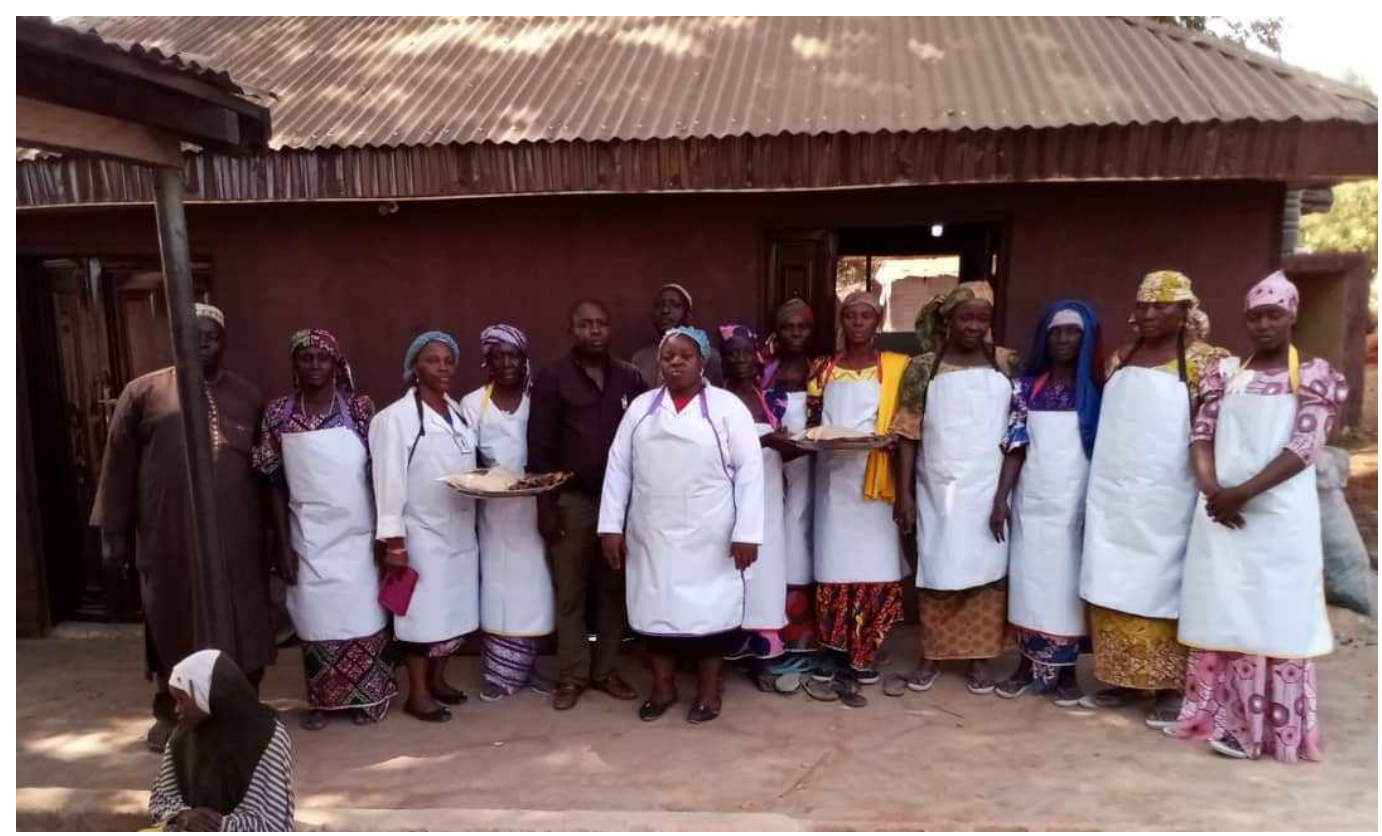

Figure 6. Participants in Tatabu Community 


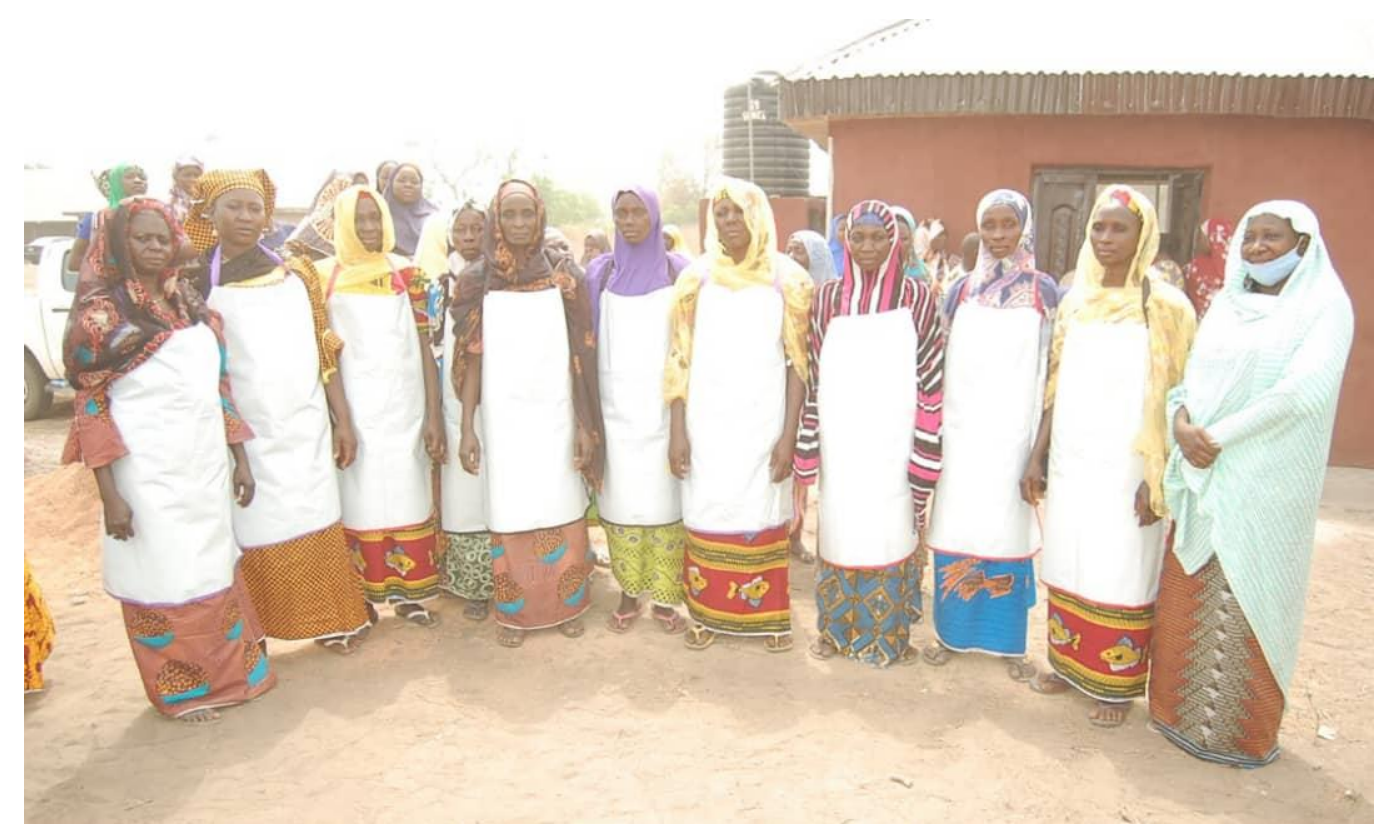

Figure 7. Participants in Tsafa Community

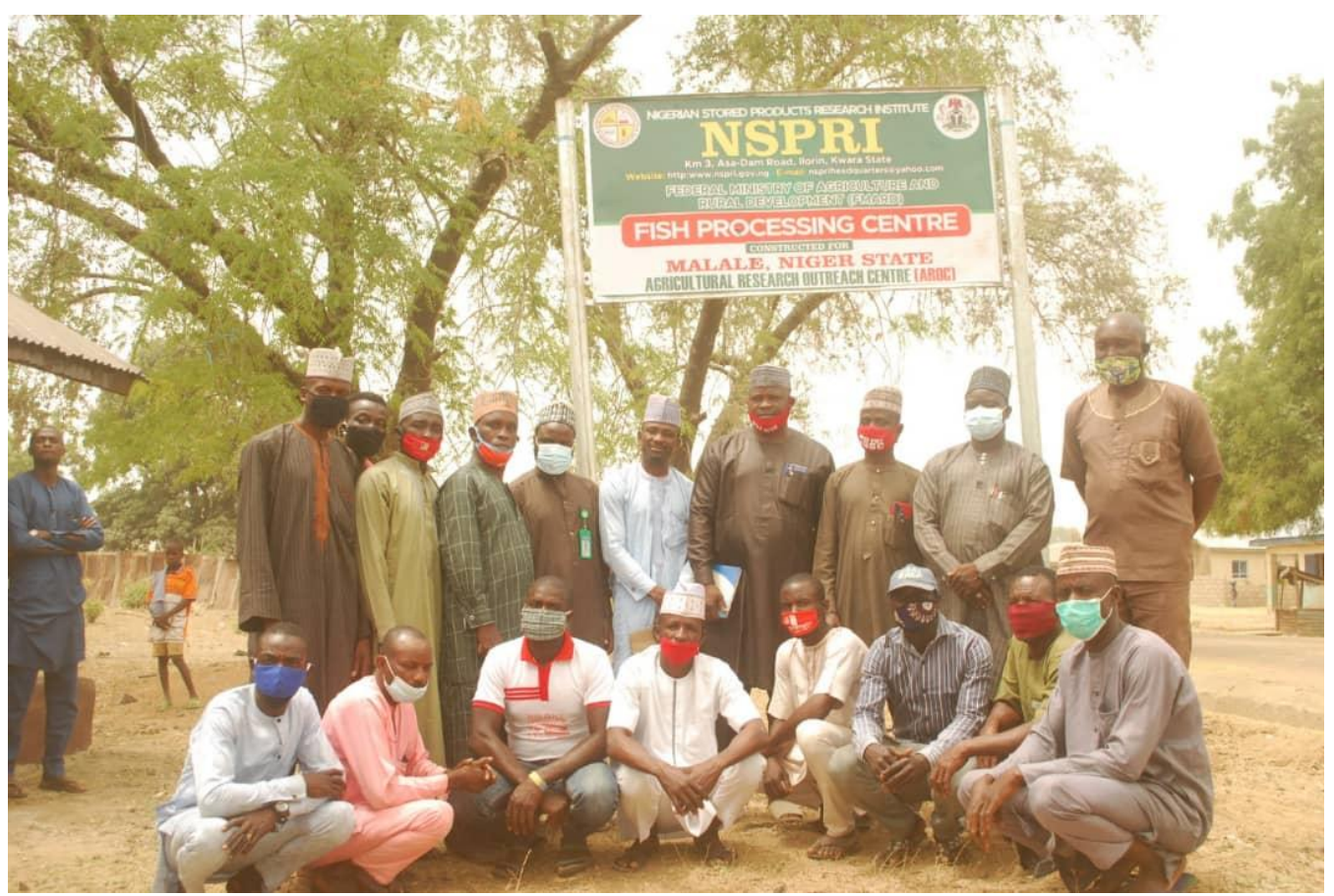

Figure 8: Participants in Malale Community

One of the critical operations of this value addition that can enhance safety and quality of the fish is thorough washing with clean water. The participants were diligently taken through this process and allowed to practise it in line with what they learnt. Another key step in the protocol flow chart was giving the fish unique taste of choice. In this case, salt was used. A brine solution was prepared using a ratio of $1 \mathrm{~g}$ of salt: 1 litre of water to handle $1 \mathrm{~kg}$ of fish. The fish was soaked for 30 minutes in the solution to achieve the aim. After the lapse of the time, they drained the solution off and arranged the fish on the drying trays in preparation for loading into the kiln. Another important information passed across to the participants ahead of loading was on disinfection of the kiln. It is very important to charge the energy source and pre-heat the kiln for 10 minutes to disinfect the chamber. Thereafter, the 
fish on the trays were loaded into the kiln and the operation commenced. It lasted for 8 hours before the drying was completed and the product reached safe moisture content. The product was allowed to cool before packaging to prevent condensation in the packaging material because of heat build-up. The processed fish from the NSPRI Smoking Kilns ${ }^{\circledR}$ was compared with the locally processed ones and the participants attested to the better quality of the smoke-dried fish (Figure 9).

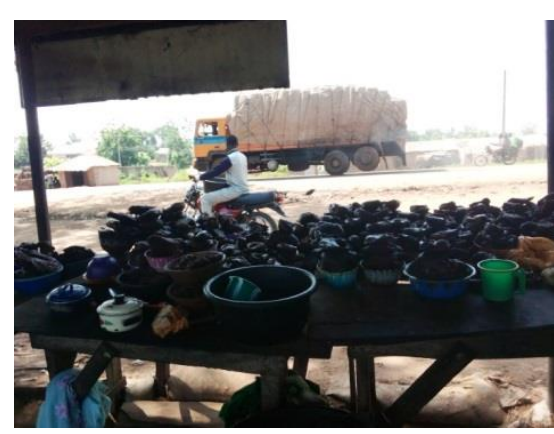

a: Locally processed fish
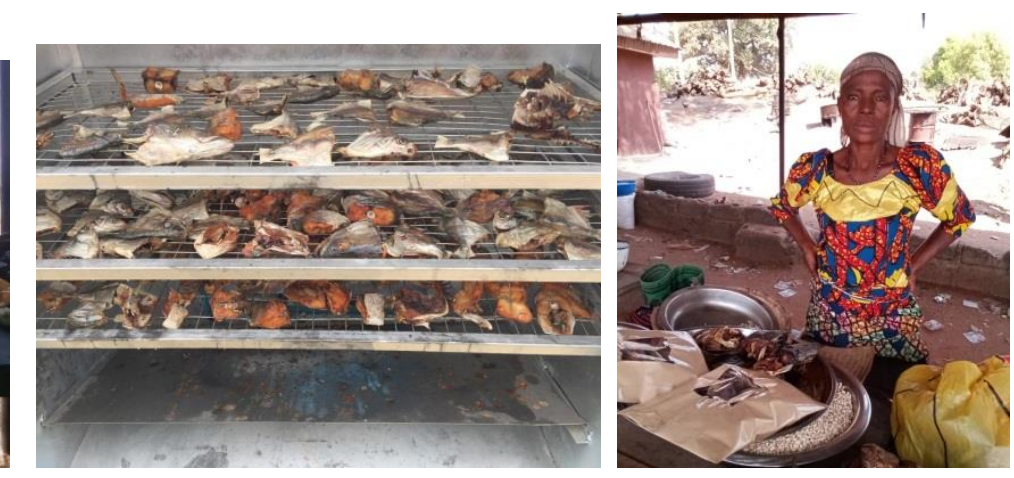

Figure 9: Comparison of smoked fish with NSPRI Kiln® and traditional method.

Irrespective of the effort put into processing of the fish like other products, if provision is not made for adequate packaging, the input can end up in the drain. To avert this, the participants were exposed to importance of fish packaging and how it could be done with minimal cost. Available packaging of different sizes made of high-density polythene was adapted and provided for each community with customized label. With this improvement, their products last longer and are free of dust and flies. Despite the presence of the pandemic after the intervention, the patronage has greatly improved with increase in income of the beneficiaries. Finally on the training, the participants were exposed to maintenance of the smoking kiln and the entire facilities in the centre to sustain their functionality and extend the lifespan of the facilities. The beneficiaries at each centre agreed on the convenient modality to maintain and sustain the centre. The three communities expressed their gratitude during the official commissioning of each centre. The beneficiaries also stated their views concerning the intervention as timely, appropriate, adequate, poverty-eradicating and livelihood sustenance especially during a global pandemic like COVID-19.

\section{Conclusion}

The impact of the COVID-19 pandemic is still being felt in many rural communities leaving more people vulnerable day by day. This effect cuts across many sectors of Nigeria economy (fisheries inclusive) and the socio-economic status of the populace. However, supports from both governmental and non-governmental organizations can go a long way to succour and boost the people's resilience to the effects of the pandemic on their livelihood. No doubt, the Federal Government's intervention to the fishing communities through NSPRI is lauded by the beneficiary communities and has potentials to cushion the effects of the COVID-19 pandemic by reducing the loss on fisheries, increasing the beneficiaries' income, and making safe smoked fish products available for both local and international markets. This intervention has alleviated the sufferings of the vulnerable rural communities and improved their social economic status and has proven that putting such facilities in place for the needy stakeholders can alleviate difficulties in future occurrences. 


\section{References}

Africa Press Office. (2020, April 27). Coronavirus - Africa: COVID-19 could not have come at a worse time for vulnerable communities across West Africa. CNBC Africa. https://www.cnbcafrica.com/africa-press-office/2020/04/27/coronavirus-africa-covid-19could-not-have-come-at-a-worse-time-for-vulnerable-communities-across-west-africa/.

Akinola, O.A., Akinyemi, A. A. and Bolaji, B. O. (2006). Evaluation of traditional and solar drying system towards enhancing fish storage and preservation in Nigeria (Abeokuta Local Government as a case study). Journal of Fisheries International, 1(2-4):44-49.

Dada, O. A., Nwaehujor, I. U., Ige, I. M., Adebayo, O. B., Adedeji, A. Y., Ibrahim, A. S. \& Oyebanji, A. O. 2020. Quality assessment of fish oil obtained during smoke-drying of catfish (Clarias Gariepinus). Book of Abstract of Annual National Conference on Bioscience and Biotechnology (virtual), BBC 65: 85.

Food and Agriculture Organization-FAO. (1992). Review of the state of the World Fisheries Resources, Part I. The marine Resources, "FAO Fisheries Circular 7, I 0, Rev.8.

FAO. 2020. The State of World Fisheries and Aquaculture 2020. Sustainability in action. Rome. https://doi.org/10.4060/ca9229en

Francisco, F., Dean, M. J., and Espen, B. P. (2015). The international poverty line has just been raised to $\$ 1.90$ a day, but global poverty is basically unchanged. How is that even possible? https://blogs.worldbank.org/developmenttalk/international-poverty-line-has-just-beenraised-190-day-global-poverty-basically-unchanged-how-even

GFCM (2020, July 1). Webinar on the experience of the aquaculture sector through best practices and mitigation measures. http://www.fao.org/gfcm/meetings/info/en/c/1398619/

Harper, S. Adshad,e M, Lam V. W. Y. Pauly, D. Sumaila, U. R. (2020). Valuing invisible catches: Estimating the global contribution by women to small-scale marine capture fisheries production. PLOS ONE, 15(3): e0228912. https://doi.org/10.1371/journal.pone.0228912.

Harvey, R. (2020, April 9). COVID-19: The unseen impacts on children. UNICEF East Asia \& Pacific. https://blogs.unicef.org/east-asia-pacific/covid-19-the-unseen-impacts-on-children/.

HLPE (2020, March 23). Initial estimates of the International Labour Organization (ILO) indicate a significant increase in unemployment and underemployment in the wake of the pandemic draft HLPE Issue paper. https://www.ilo.org/global/about-theilo/newsroom/news/WCMS_738742/lang-en/index.htm

Mohammed, S. B., Mohammad, I. F., Pangirayi, T. B., Vernon, G., Dzidzienyo, D. K., Umar, M. L., and Umar, S. (2020). Farmers' knowledge, perception, and use of phosphorus fertilization for cowpea production in Northern Guinea Savannah of Nigeria. Heliyon, 6(10), 1-9. https://doi.org/10.1016/j.heliyon.2020.e05207

Nigerian Stored Products Research Institute - NSPRI (2021). About NSPRI. NSPRI official website. Accessed on April 21, 2021. https://www.nspri.gov.ng > index.ph

Nti, C., Plahar, W. and Larweh, P. 2002. Impact of adoption in Ghana of an improved fish processing technology on household income, health and nutrition. International Journal of Consumer Studies, 26(2):102-108.

Omodara, M. A., Olayemi, F. F., Oyewole, S. N., Ade, A. R., Olaleye, O. O., Abel, G. I. and Peters, O. (2016). The drying rates and sensory qualities of African catfish (Clarias Gariepinus) dried in three NSPRI developed fish kilns. Nigerian Journal of Fisheries and Aquaculture, 4(1): 42 49.

Orlowski, A. (2020, April 27). Small-scale fishermen suffering significantly from COVID-19 pandemic. Seafood Source. https://www.seafoodsource.com/news/supply-trade/small-scalefishermen-suffering-significantly-from-covid-19-pandemic. 
Sanni, A. O., Ayanda, J. O., Alhassan D. A., Adebayo C. O., and Bako W. S. (2012). The concept of adopted villages and agricultural research outreach centres - implication for fisheries development in Nigeria- a review. In the Proceedings of $26^{\text {th }}$ Annual Conference of the Fisheries Society of Nigeria (FISON). 48-53. http://hdl.handle.net/1834/38767

Simona V. (2020, November 3). Literacy rate in Nigeria 2018, by zone and gender. Statistica. https://www.statista.com/statistics/1124745/literacy-rate-in-nigeria-by-zone-and-gender/

The World Bank. 2012. Hidden harvest: The global contribution of capture fisheries. 66469GLB. Washington, D.C.: The World Bank.

Turkewitz, J. (2020, April 9) Indigenous groups isolated by coronavirus face another threat: hunger. The New York Times. https://www.nytimes.com/2020/04/09/world/americas/indigenous-coronavirus-hunger.html.

Welsh, T. (2020, April 22). World Food Programme Chief Warns of 'hunger Pandemic' as COVID19 threatens food security. Devex (blog). https://www.devex.com/news/sponsored/wfp-chiefwarns-of-hunger-pandemic-as-covid-19-threatens-food-security-97058. 